\title{
Predicting Garment Appearance Quality
}

\author{
Daniela Zavec Pavlinic ${ }^{*}, 1,2$ and Jelka Geršak ${ }^{1}$ \\ ${ }^{1}$ University of Maribor, Faculty of Mechanical Engineering, Department of Textile Materials and Design, Slovenia \\ ${ }^{2}$ Biomed d.o.o., Ljubljana, Slovenia
}

\begin{abstract}
Developing steps in designing a system for predicting garment appearance quality are presented. The articles of clothing investigated are ladies' jackets and the accent is given to subjective evaluation of individual factors of garment appearance quality. A group of semi-skilled evaluators and a group of experts in the field of garment engineering were doing the evaluation. This system of dual evaluation and comparison of the grades obtained are key factors in the development of the predicting models using the method of machine learning. The algorithms of the latter are implemented in the Orange machine learning system, which was used to develop the system for predicting garment appearance quality grade. It is founded on previous knowledge of correlations among the quality grade of a particular factor of garment appearance quality and the parameters of mechanical and physical properties of the analysed fabrics, incorporated into the garments in question. The workings of the system designed result in a prediction of garment appearance quality grade, presented separately for each individual factor of appearance quality defined.
\end{abstract}

Keywords: Textile, garment appearance, quality, subjective estimation, mechanical properties, prediction.

\section{INTRODUCTION}

Garment quality is not determined by the quality of manufacture only, but by a number of other influential factors as well. The most important of them are construction and the quality of the fabrics incorporated in the garments. The garment shaped and manufactured so that it fits the 3D shape of the human body should meet the criteria of appearance quality and comfort in wearing. In the course of manufacturing, the fabrics from which the garments are made, due to their anisotropic properties, behave in different ways under the loads occurring. Their behaviour depends upon their mechanical and physical properties. Formability of the fabrics in particular garment manufacturing processes, and the stability of the newly created form, directly impact garment appearance quality. Additionally, an important role in ensuring the quality of the garment made is played by the additional factors, such as drape, fitting to the anatomic parts of the body, ensuring complete 3D shape and the quality of the appearance of the seams made [1]. These factors cannot be measured, but can easily be evaluated with descriptive grades, visual by nature and subjective. However, descriptive grades present a problem in evaluating garment appearance quality grade, i.e. particular factors and the appearance as a whole, since inconsistencies occur and inability to compare evaluation of garment appearance quality grade among the manufacturers and among the end-users as well. There are no standards available that could be used as a guide in garment appearance quality evaluation. This is why a subjective

*Address correspondence to this author at the University of Maribor, Faculty of Mechanical Engineering, Department of Textile Materials and Design, Slovenia; E-mail: daniela.z-pavlinic@uni-mb.si method of evaluation is employed, based on experience and arbitrarily set requirements for evaluating appearance quality of particular articles of clothing. Subjective evaluation of quality is widely accepted and its importance respected, since with experience it has become highly sophisticated. However, the problem is that the subjective method, not so easily acceptable from the scientific point of view, does not offer engineering evaluation of garment quality. This is why it is necessary to develop an exact method to obtain an objective evaluation of garment appearance quality.

The paper presents a method of predicting garment appearance quality, based on studying the interactions between the parameters of fabric mechanical and physical properties, as measurable values, and garment appearance quality grade, expressed by descriptive subjective grades. The method presented of subjective evaluation of garment appearance quality is based on a precisely designed control system, aimed at defining elements important for appearance quality. They represent 5 key factors of garment appearance quality, and include proper drape, i.e. garment yield, 3D shape, garment fit, the quality of the seams made and the quality of the garment appearance as a whole. To reach this goal, the first step included subjective evaluation of garment appearance quality in the course of manufacturing, as well as the additional evaluation based on pictorial representation of particular articles of clothing. Parameters of mechanical and physical properties of the fabrics included in the garments were determined for all the garments analysed using the KES-FB AUTO measuring system, and correlations were established among the individual parameters of fabric mechanical properties and garment appearance quality. This correlation is essential, since it constitutes previous knowledge in the development of the system for predicting garment appearance quality. 


\section{STEP-BY-STEP INTO THE PREDICTION OF THE GARMENT APPEARANCE QUALITY}

The approach to the theory of evaluating garment appearance quality asked for specific knowledge in the field of domains. The road to the development of an intelligent system for predicting the factors of garment appearance quality can be described in steps. Since fabric is, together with auxiliary materials built into the garment, such as interlinings and linens, basic building element of a garment, the first step included studying fabric properties, from the point of view of fabric construction, their mechanical properties. Namely, the appearance of the garment manufactured, i.e. its quality, is realised as a harmony of the materials built into the garment. The next step was defining the criteria and elements of garment appearance quality, specific for a particular article of clothing, in this case ladies' outerwear. Selected definitions of particular factors of quality were a basis for subjective evaluation of garment appearance quality. The analysis of the correlation between the parameters of fabric mechanical and physical properties and the subjective evaluation of garment appearance quality was used in the third step to start developing an intelligent system for predicting garment appearance quality.

\subsection{Fabric}

Fabric is a 2D textile product, created by interlacing and interlocking two or more thread systems at right angle [2]. Fabric construction parameters, associated with the structure and properties of the fibres and the yarns used, fabric construction, the manner of patterning and technological processes of manufacture are primary factors, while the weave, density and fineness of the yarns are secondary ones. The later are dependent on fabric mass and thickness, yarn insertion, fabric surface cover and its fullness [3].

When studying mechanical behaviour of fabrics it is necessary to have in mind their inhomogeneity and anisotropy, which contribute to the fact that that considerable fabric deformation is likely to occur even at lower loads [46]. Fabrics are, together with the auxiliary materials, exposed to low loads in garment manufacturing processes, i.e. in the processes aimed at transforming fabrics from $2 \mathrm{D}$ into a $3 \mathrm{D}$ shape of a garment, as well as in end-use of a garment. Loads can be classified as tensile, compressive, shear, bending and torsional. Each particular load, or a combination of them, has a definite importance in garment industry. Since fabrics behave non-linearly in the processes of garment manufacture, determining their mechanical properties is a complex job. However, it is a necessary prerequisite for the engineering prediction and designing of high-quality parameters of textiles and garment quality accordingly [4].

The origins of objective measurement of textile fabric mechanical properties, with practical application in the textile and garment industries, can be traced as far as the seventies, when the system for measuring textile fabric mechanical properties at lower loads, so called KES measuring system [7] was developed. Objective evaluation of fabric mechanical and physical properties for the purpose of this investigation was accomplished using the computeraided measuring system KES - FB AUTO, where particular parameters are, based on the manner of exerting load, divided into 6 sets:

- Set 1: tensile properties (elongation EMT - \%; deformation work $\mathrm{WT}-\mathrm{cNcm} / \mathrm{cm}^{2}$; relaxation ability RT - \%; linearity LT; ratio of extensions $\alpha=\mathrm{EL} 2 / \mathrm{EL} 1)$

- Set 2: shear properties (shear rigidity $\mathrm{G}-\mathrm{cN} / \mathrm{cm} . \mathrm{st}$; shear hysteresis at $\pm 0,5^{\circ} 2 \mathrm{HG}-\mathrm{cN} / \mathrm{cm}$; shear hysteresis at $\pm 05,0^{\circ} 2 \mathrm{HG} 5-\mathrm{cN} / \mathrm{cm}$ )

- Set 3: bending properties (bending rigidity $\mathrm{B}-\mathrm{cNcm}^{2} /$ $\mathrm{cm}$; bending hysteresis $2 \mathrm{HB}-\mathrm{cNcm} / \mathrm{cm}$ )

- Set 4: compressive properties (deformation work at the compression of $\mathrm{WC}-\mathrm{cNcm} / \mathrm{cm}^{2}$; relaxation ability $\mathrm{RC}-$ $\%$; linearity LC)

- Set 5: surface properties (friction coefficient MIU; mean absolute declination of the friction coefficient MMD; geometric roughness $\mathrm{SMD}$ - micron)

- Set 6: mass per unit area $-\mathrm{W}\left(\mathrm{g} / \mathrm{m}^{2}\right)$ and thickness $-\mathrm{h}$ (mm)

\subsection{Garment Appearance Quality}

The notion of quality usually invokes a positive idea and can be defined as the property of perception, a feeling and idea that is generally not perceived as something quantitative [8]. It can also be defined as a property that can be either positive or negative. Thus it is possible to determine the quantity of the materials built into the garments. However, subjective determination of quality is quite often associated with problems and definitely not precise. Although garment appearance quality cannot be measured, it can still be evaluated employing subjective grades of the visual appearance of garment form. Of course, it can only be done when the garment is completed. Comprehensive investigation and analysis of the fabrics built into the garment in question can, together with the information obtained through learning, say something on garment quality, even before the actual manufacture starts. The need for objective evaluation of garment appearance quality is more and more urgent with increasing market requirements, since these requirements are supposed to be met in as short a time as possible and at as low costs as possible. It means it is necessary to integrate the knowledge already obtained, past experience and fast and flexible implementation of computer tools into predicting systems, which will play, through application in industrial practice, an important role in further development of garment industry.

Garment appearance quality, i.e. properties that can be evaluated visually, is a reflexion of subjective feeling of the visual appearance and of perceiving garment form. The form or shape of an article of clothing can be, from the engineering point of view, defined as the appearance of the garment on the body, which can, in accordance with its function and construction, logically connect various shapes, forms, volumes and materials, into a harmonious composition of an article of clothing [1]. It is defined as a workpiece, where in processing, with no direct physical changing of the material, a $2 \mathrm{D}$ textile fabric is changed into a $3 \mathrm{D}$ shape. Such a mechanism of transformation is present in manufacturing ladies outerwear, i.e. jackets. These garments 


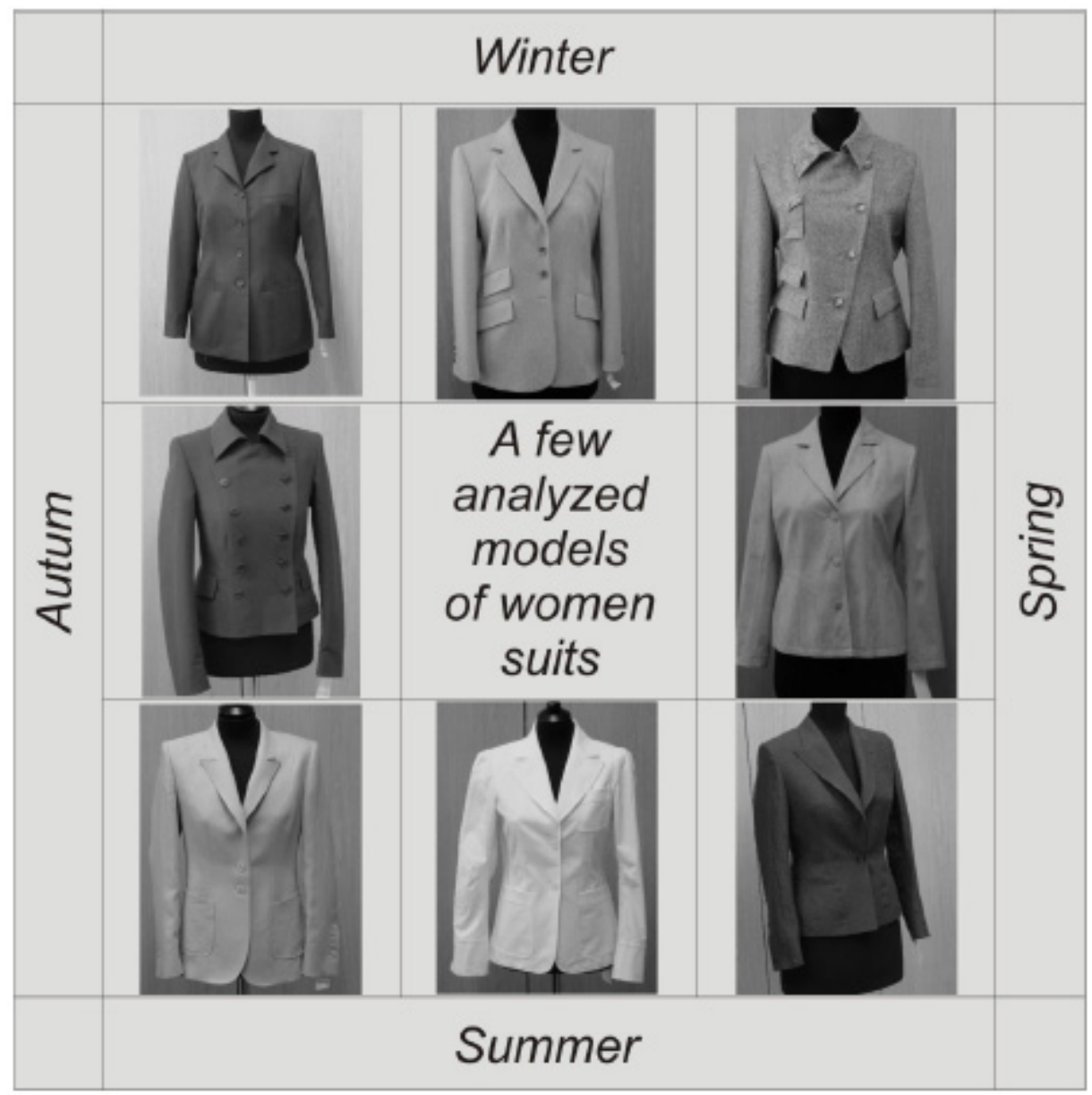

Fig. (1). Some of the randomly selected models of ladies' jackets.

contain various straight and curved seam lines and various materials are used in their manufacture, such as linings, interlinings and shoulder pads, all this with the aim to ensure: proper drape or yield of the garment, $3 D$ shape, garment fit, the quality of the seams made, as well as the quality of garment appearance as a whole [9].

\subsection{Designing the System for Predicting Garment Appearance Quality}

The notion of designing a system for predicting garment appearance quality was presented for the first time by J.Geršak [10] in 2001. The first step of the development was determining and defining garment appearance quality factors and establishing a logical approach to designing the system for predicting garment appearance quality. Since garment appearance quality cannot be measured, subjective evaluation of the quality is performed employing grades of the visual appearance of garment form, the most important factors being the aesthetic appearance, determined by garment drape, and visual appearance of the quality of the seams made, stability of the $3 \mathrm{D}$ form and the quality of the fit.

Garment appearance quality depends on the properties of the materials built into the garment, i.e. fabrics. To understand fabric behaviour in the processes of transformation into a $3 \mathrm{D}$ form of the garment, it is necessary to know fabric non- linear mechanical properties under the impact of low loads. This means that investigating the interactions between the parameters of fabric mechanical and physical properties, as measurable values, and the grade of garment appearance quality, i.e. the grade of each individual garment appearance factor, evaluated through subjective grades, offers a sound foundation for constructing a data basis and designing a system for predicting garment appearance quality.

\section{MATERIALS AND METHODS}

\subsection{Models of Ladies' Jackets}

Randomly selected models of ladies' jackets (566 different models) were taken for the purpose of investigation. They were launched for the autumn/winter season and partially for the spring summer one and some of them can be seen in Fig. (1). Due to fast-changing fashion trends, and with no sharp boundaries between seasons, the fabrics used in manufacture of the jackets analysed differ by construction parameters, as well as by their mechanical and physical properties. Construction parameters were defined following the accepted standards (raw material content by DIN 6001; yarn density by DIN 53853 , mass per unit area by DIN 53854, weaves by DIN 61101), while the parameters of mechanical and physical properties were determined using the KES-FB AUTO measuring system and the FAST -4 testing method [7, 11-15]. 
Table 1. Factors of Garment Appearance Quality

\begin{tabular}{|c|c|c|}
\hline Criteria Mark & $\begin{array}{c}\text { Elements of Garment Appearance } \\
\text { Quality }\end{array}$ & Determination \\
\hline \hline A & Garment fall and draping & Fall of the front/back part and sleeves, adjustment of different components and materials \\
\hline B & Assuring 3D shape of a garment & $\begin{array}{c}\text { Quality of the form, its spatial characteristics, fullness of the front part, volume adjustment, } \\
\text { shoulder and sleeve form }\end{array}$ \\
\cline { 1 - 3 } C & Garment fit & Fitting the shoulder to the contour of the body, fitting the front part and collar \\
\cline { 1 - 3 } D1 & Quality of the seams & Seam puckering \\
\hline D2 & \multicolumn{2}{|c|}{ Seam flotation, shear deformed seam } \\
\hline E & \multicolumn{2}{|c|}{ Garment appearance quality as a whole } \\
\hline
\end{tabular}

\subsection{Control System of the Subjective Evaluation}

The factors of garment appearance quality were determined on the basis of the elements for obtaining proper drape, i.e. garment yield, achieving 3D shape, garment fit, the quality of the seams made and the quality of garment appearance as a whole. Having this in mind, a proper control system was designed, based on defining elements important for garment appearance, (Table 1) [16].

Individual factors were subjectively evaluated, so that the appearance quality grade of the factor was evaluated with grades from 1 (low quality) to 5 (excellent), in the course of garment manufacture. The criteria for grading individual factors of garment appearance quality are provided. Each description of the criterion is accompanied with a pictorial representation of the garment manufactured [16].

Each individual factor of garment appearance quality was graded by semi-skilled evaluators. The complexity of the method of subjective evaluation asked for a basis of pictorial representation of the garment evaluated and proper storing of the data for later use. Experts in the field of garment engineering were later on also asked to grade the individual factors of appearance quality. The grades obtained were used to cross check the accuracy of the predicted garment appearance quality.

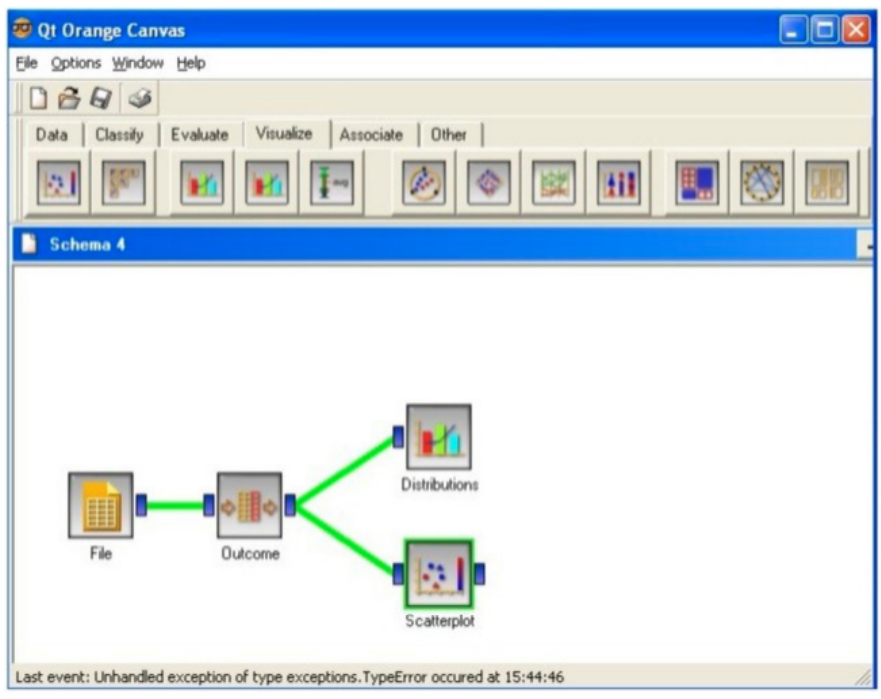

a)

\subsection{Attributes, Classes and Learning Subsets}

Parameters of mechanical and physical properties represented the attributes in solving the problem of predicting garment appearance quality employing machine learning, while the individual quality factors were classes. All the attributes were mutually connected. There were six different classes to be predicted (Table 1). As they had five values each, clearly defined but not necessarily equidistant, no commonly used method of machine learning was able to deal with them properly and completely. In practice, we had to choose a discrete manner of work, neglecting the values defined or the common (regression) definition, since we dealt with five different values and the differences among them were not equidistant. Preliminary trials showed that regression was more appropriate for the problem, as it offered much more accurate and transparent models [17].

An expert had, on the basis of his previous knowledge, determined attribute characteristics, which were, in his opinion, most important for a particular factor of garment appearance quality. The previous knowledge used included, on one hand, the studies of subjective evaluations of garment appearance quality, and on the other the studies of mechanical and physical properties of the fabrics analysed, augmented by the knowledge of correlation with the garment

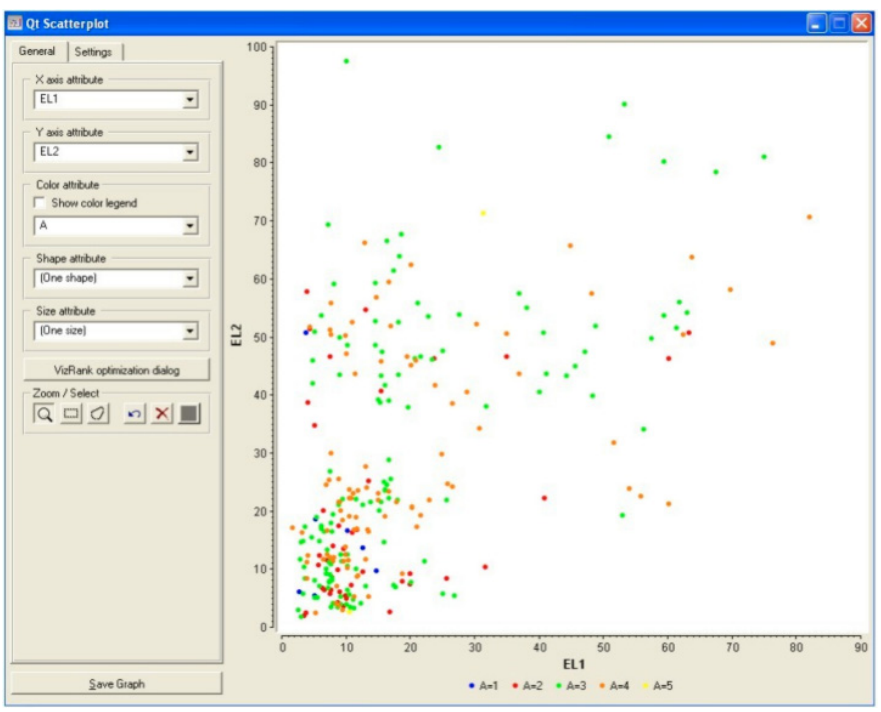

b)

Fig. (2). Orange Canvas: a) with graphic abilities of reading the data, selection of the class monitored and drawing a histogram, and b) diagram. 
appearance quality grade of particular factors, which offered the data on the fabric analysed through the parameters of mechanical and physical properties. Learning patterns were designed, to be used in the method of machine learning to design a system for predicting appearance quality grade of the ladies' jackets.

\subsection{Program Tool}

After preliminary trials, the following methods of machine learning were used to design the prediction model: construction of regression trees and the method of nearest neighbours k-NN. Due to poorer results regarding prediction accuracy, the methods of loaded linear regression, naïve Bays classifier and learning with association rules were rejected as appropriate methods for the purpose. Between the selected methods, i.e. regression trees and k-NN nearest neighbours, the last one offered better results regarding prediction accuracy, proving thus to be more appropriate for predicting garment appearance quality. The algorithm of the $\mathrm{k}-\mathrm{NN}$ method of nearest neighbours was applied into the system of machine learning Orange [18]. The system also includes some components of the other methods of machine learning mentioned, as well as the components for preprocessing of the data and evaluation of learning results. The system is particularly appropriate for studying the impact of the parameters of fabric mechanical and physical properties on the factors of garment appearance quality, and prediction of them, as it can be used through the user-friendly Orange Cavnas graphic interface (Fig. 2), and through the script language python, which offers designing the procedures of data processing and learning, specifically designed for a particular problem.

An example of the script in the python language is offered, using the data from six different filed and the grade for the model quality, designed with the algorithm of knearest neighbours, learning with regression trees and the classification with majority class (Fig. 3).

\subsection{Spearman Rank Correlation}

Numerous data are needed to perform a prediction, since it is necessary to compare the predicted values with the

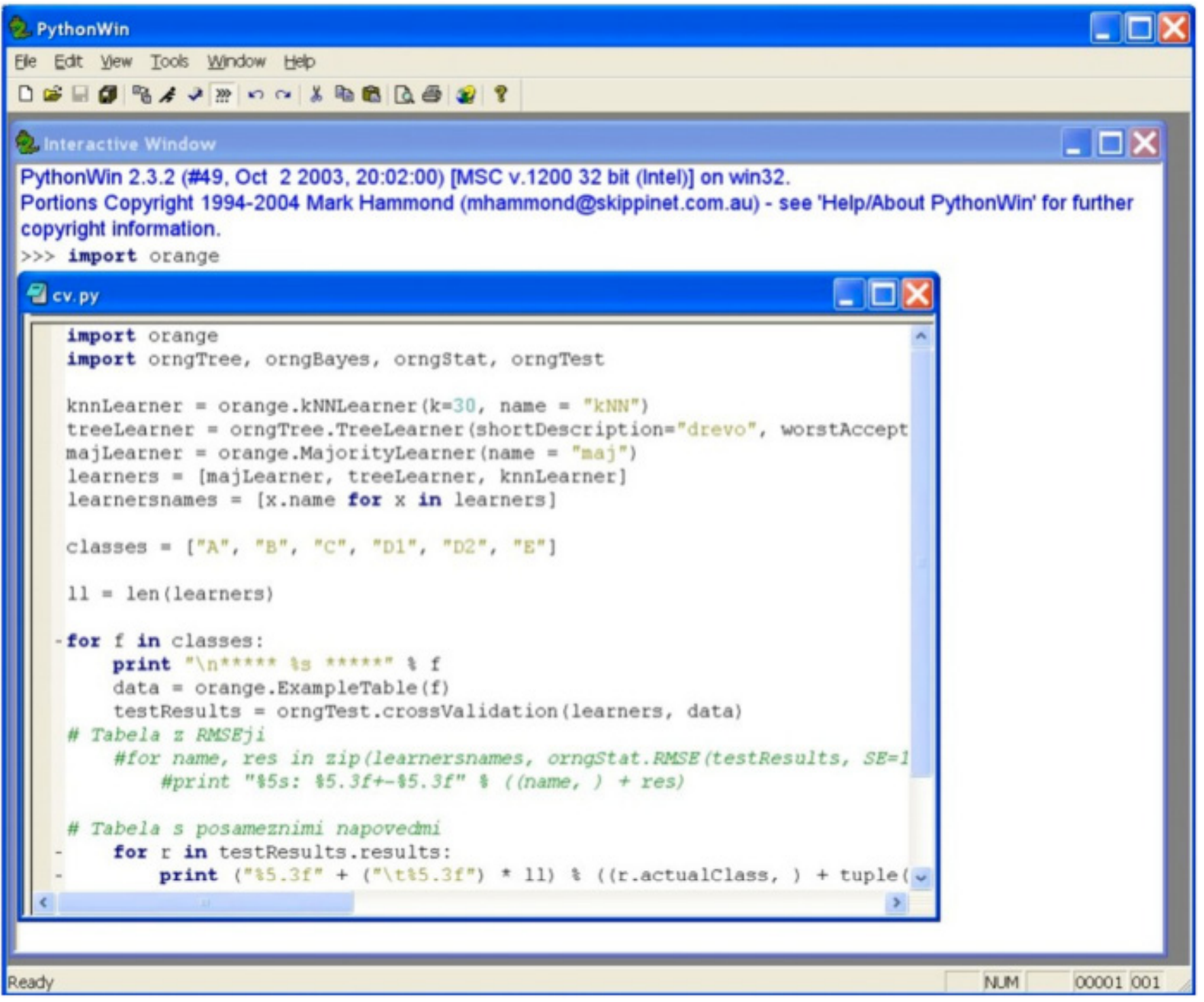

Fig. (3). An example of the script for the Orange in the python programming language. 
Table 2. The Results of the Spearman Coefficient of Rank Correlation $\rho$ of the Grades Offered by Semi-Skilled Evaluators and Experts

\begin{tabular}{|c|c|c|}
\hline \multicolumn{2}{|c|}{ Elements of Garment Appearance Quality } & Spearman's Rang Correlation Coefficient $\boldsymbol{\rho}$ \\
\hline \hline A & Garment fall and draping & 0,886 \\
\hline B & Assuring 3D shape of a garment & 0,542 \\
\hline D & Quality of the seams & 0,610 \\
\hline E & Garment appearance quality as a whole & 0,805 \\
\hline
\end{tabular}

existing examples, such that represent previous experience and already discovered regularities. It is thus necessary to process the numeric, as well as non-numeric, data in a proper way and use them to evaluate the problem to be solved. Rank correlation of non-numeric data can be determined employing the Spearman rank correlation coefficient, defined by the following equation $[19,20]$ :

$$
\rho=1-\frac{6 \cdot \sum_{i=1}^{N} D_{i}^{2}}{N\left(N^{2}-1\right)}
$$

where $\mathrm{Di}$ is the distance between the ranks, $\mathrm{i}$ is the value of both changes, $\mathrm{N}$ is the number of measurements performed. In our example, the measurements are connected with the attributes, which are determined in the first rank (ranked by importance) by the experts in the field of garment engineering, while in the second rank they are ranked by the importance of numbers, or how many times is a particular attribute used to predict among the 30 repeated trials, using the method of nearest neighbours (k-NN). The attributes represent the parameters of mechanical and physical properties.

\section{RESULTS AND DISCUSSION}

The results of studying the impact of the parameters of fabric mechanical and physical properties on the factors of garment appearance quality are determined using the grades of garment appearance quality factors, as presented by the semi-skilled evaluators and by the experts in the field of garment engineering, regarding the individuals factors of garment appearance quality, as well as using the accuracy grades from the prediction of garment appearance quality.

\subsection{The Results of Subjective Evaluation of Garment Appearance Quality}

Having in mind the aim of the investigation, i.e. to study the impact of the parameters of fabric mechanical and physical properties on the garment appearance quality grade, and to establish a system for predicting garment appearance quality grade, the first step, after the evaluation of garment appearance quality, included an adequate analysis of the value of the grades, offered by semi-skilled evaluators in the course of manufacture and the grades offered by the experts in garment engineering, based on pictorial representations. The analysis of the correlation between these two evaluations, for particular factors of garment appearance quality, was calculated using the Spearman rank correlation, (Table 2).

When evaluating on the basis of pictorial representation, the quality of garment fit was not included, since it is almost impossible to grade garment drape and fit on the basis of a pictorial representation only. The analysis of the results of subjective evaluation indicate that when evaluating visually and subjectively, various evaluators expressed different standpoints regarding the pre-determined criteria of quality grad that was evaluated. The analyses performed were then used to compare the accuracy of the prediction of garment appearance quality grade using the system developed.

\subsection{The Results of Determining Attribute Characteristics}

A data basis, ready to be used, was prepared after the factors of garment appearance quality, of ladies' jackets, and determining the parameters of mechanical and physical properties of the fabrics used, employing the KES - FB AUTO measuring system and the FAST - 4 testing method. Learn-

Table 3. Attributes that Impact Particular Factors of Garment Appearance Quality

\begin{tabular}{|c|c|c|}
\hline $\begin{array}{c}\text { Elements of Garment } \\
\text { Appearance Quality }\end{array}$ & $\begin{array}{c}\text { Mark of the } \\
\text { Element }\end{array}$ & Mark of the Particular Factor \\
\hline \hline Garment fall & A & W, 2HG5-1, 2HG5-2, EL-1, EL-2, 2HB-1, 2HB-2, RT-1, RT-2, 2HG-1, 2HG-2, WT-1, WT-2 \\
\hline Shape & B & W, F-1, F-2, RT-1, RT-2, 2HB-1, 2HB-2 \\
\hline Fit & C & B-2, F-2, 2HG5-2, F-1, 2HG5-1, 2HB-2 \\
\hline Seam puckering & D1 & B- RT-1, EMT-1, EL-2, EL-1,2HG-2, 2HG5-2 \\
\hline Seam flotation & D2 & W, F-1, F-2, 2HG5-1, 2HG5-2, EL-1, WT-1, WT-2, SMD-1, RS-2, HE-1 \\
\hline Appearance & E &
\end{tabular}


ing examples in the basis were the fabrics, described by the parameters of their mechanical and physical properties, as well as by grades of garment appearance quality for the garments made from these fabrics. The parameters of fabric mechanical and physical properties were the attributed. The classes to be predicted were applied on the factors of garment appearance quality. An expert in the field of garment engineering had determined the characteristics of the attributed that had, in his opinion, the most outstanding impact on a particular factor of garment appearance quality, (Table 3).

On the other hand, as an alternative to the expert selection of the attributes, was their selection using the algorithm of k-NN. In each step, an attribute was eliminated that did not contribute to classification accuracy. The procedure of eliminating attributes was repeated for 30 times, and was stopped when further elimination would result in classification accuracy statistically lower than the one already obtained. The result was the number of how many times a particular attribute was recognised as a nonredundant one. Rankings were compared then, with the attributes grouped by their impact, by the opinion of the expert in the field of garment engineering and by ranking using the algorithm of k-NN. The attributes selected were statistically compared using the Spearman rank correlation, which proved a high correlation between these two rankings. This is why in our further work, in designing a predicting model and in testing, a selection of the attributes offered by the expert (doctoral thesis) was used.

\subsection{The Results of the Accuracy in Predicting Garment Appearance Quality}

The Spearmen coefficient of rank correlation (Table 4), was also calculated with the predicted grade values and the grades of particular garment appearance quality factors. All the Spearman rank correlations proved to be statistically relevant $(\mathrm{p}=0.01)$.

The analysis of the accuracy of the predicted grades is associated with the comparison of the predicted grades of appearance quality using the designed system and the method of k-NN, and the grade values obtained in evaluating garment appearance quality grade in the actual manufacturing process. It can be seen that the highest correlation was obtained in predicting garment fit, followed by the prediction of the appearance quality of the garment as a whole, and the prediction of the drape, i.e. yield of the garment. On the first glance, the results seemed to offer fairly low correlation between the predicted and actual grades, obtained in the course of manufacture. It could be attributed to the fact that the grades predicted by the system were taken as real numbers, rounded to one decimal place, while the grades obtained in manufacture were presented as whole numbers. It means that the values could easily differ at the start by 0.5 , e.g. that the predicted values of garment appearance quality grade, obtained using the designed system, and falling between, for example, 2.6 and 3.5, could be (and probably were) quite similar to the grade of 3, obtained in the actual manufacturing process.

\subsection{The Results of the System for Predicting Garment Appearance Quality}

The algorithm of the k-NN method of nearest neighbours was included into the user-friendly system for predicting garment appearance quality, available at the Internet. The results of measuring fabric mechanical and physical properties, obtained by the KES-FB AUTO measuring system and the FAST 4 testing method were store in numerous files. The application works so that the user inputs any of the files into the program. The program searches and reads the other files containing the data on the fabric, opens the adequate window and inserts the data into the form. All the values of the parameters of fabric mechanical and physical properties are presented in the window, (Fig. 4). The user then inserts the data on fabric mass per unit area, not included into any of the files, and corrects some other data if need be.

Clicking the button "PREDICTION OF APPEARANCE" the data are sent to the processor, which, using the Orange programming system, calculates the grades of prediction for garment appearance quality factors, (Fig. 5). The predicted grades are rounded to one decimal place, while the original grades are whole numbers. It means that if the quality grade is between 2.6 and 3.5, the description and pictorial representation are connected with the quality grade of 3 . Pictorial representations from the existing data basis only are available at the moment, and this is why there is no colour in them and no visual match between them and new, randomly selected fabrics.

Table 4. Spearman Coefficient of Rank Correlation with the Predicted Grade Value and the Value of a Particular Appearance Quality Factor

\begin{tabular}{|c|c|c|}
\hline \multicolumn{2}{|c|}{ Elements of Garment Appearance Quality } & Spearman's Rang Correlation Coefficient $\rho$ \\
\hline \hline A & Garment fall and draping & 0,526 \\
\hline B & Assuring 3D shape of a garment & 0,391 \\
\hline C & Garment fit & 0,594 \\
\hline D1 & Quality of the seams & 0,498 \\
\hline D2 & Garment appearance quality as a whole & 0,417 \\
\hline E & Ty & 0,573 \\
\hline
\end{tabular}




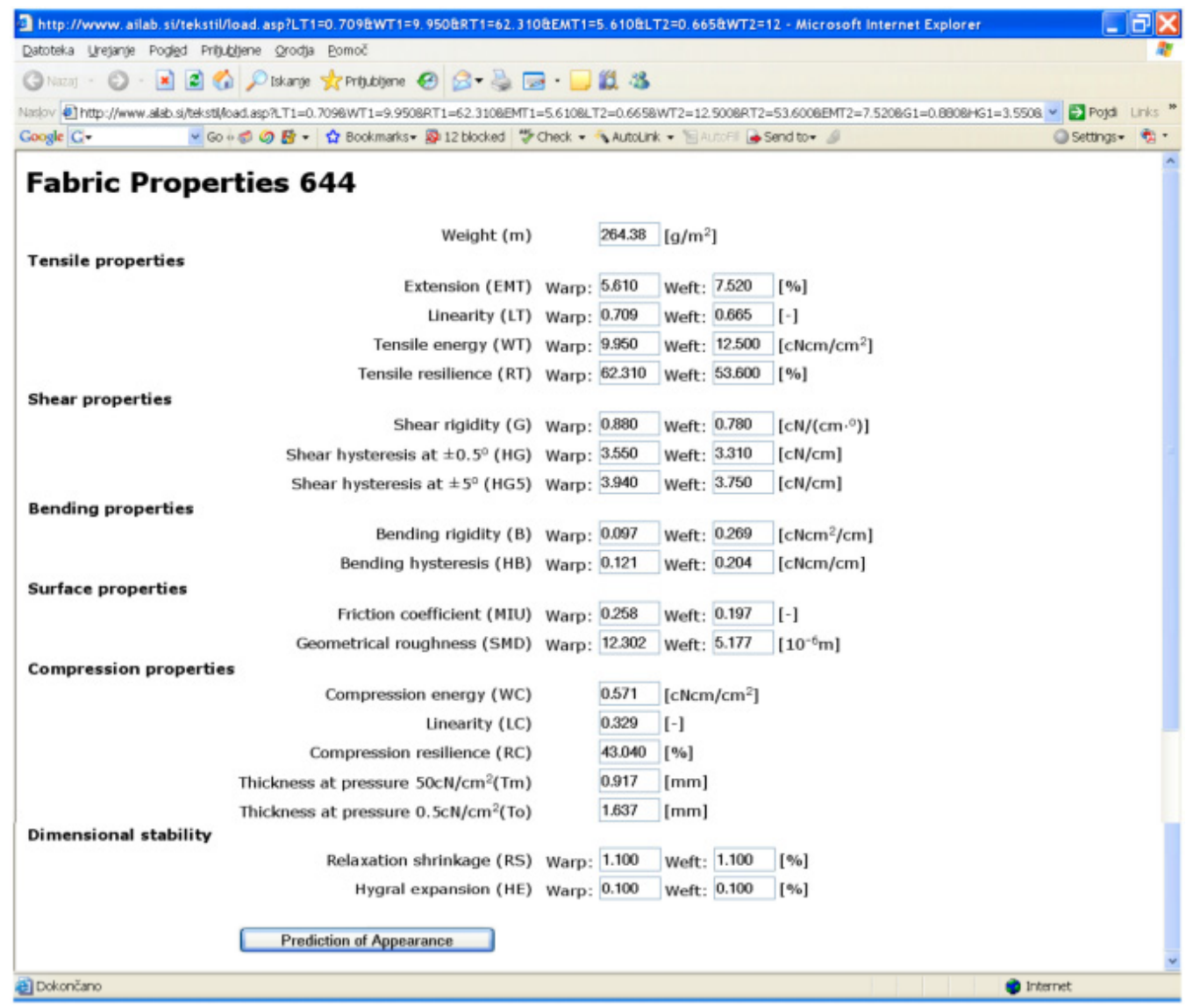

Fig. (4). Interactive window of the system for predicting garment appearance quality, with the values of fabric property parameters.

\section{CONCLUSION}

The system for predicting garment appearance quality we have designed came as a result of comprehensive investigations of fabric mechanics, as non-linear mechanical proper- ties at lower loads, the ability of the fabrics to be transformed from a plane to a 3D form of a garment and stability, e.g. appearance of the newly created form. Analysing the results obtained by investigating appearance quality of the garments tested, employing the method of machine learning

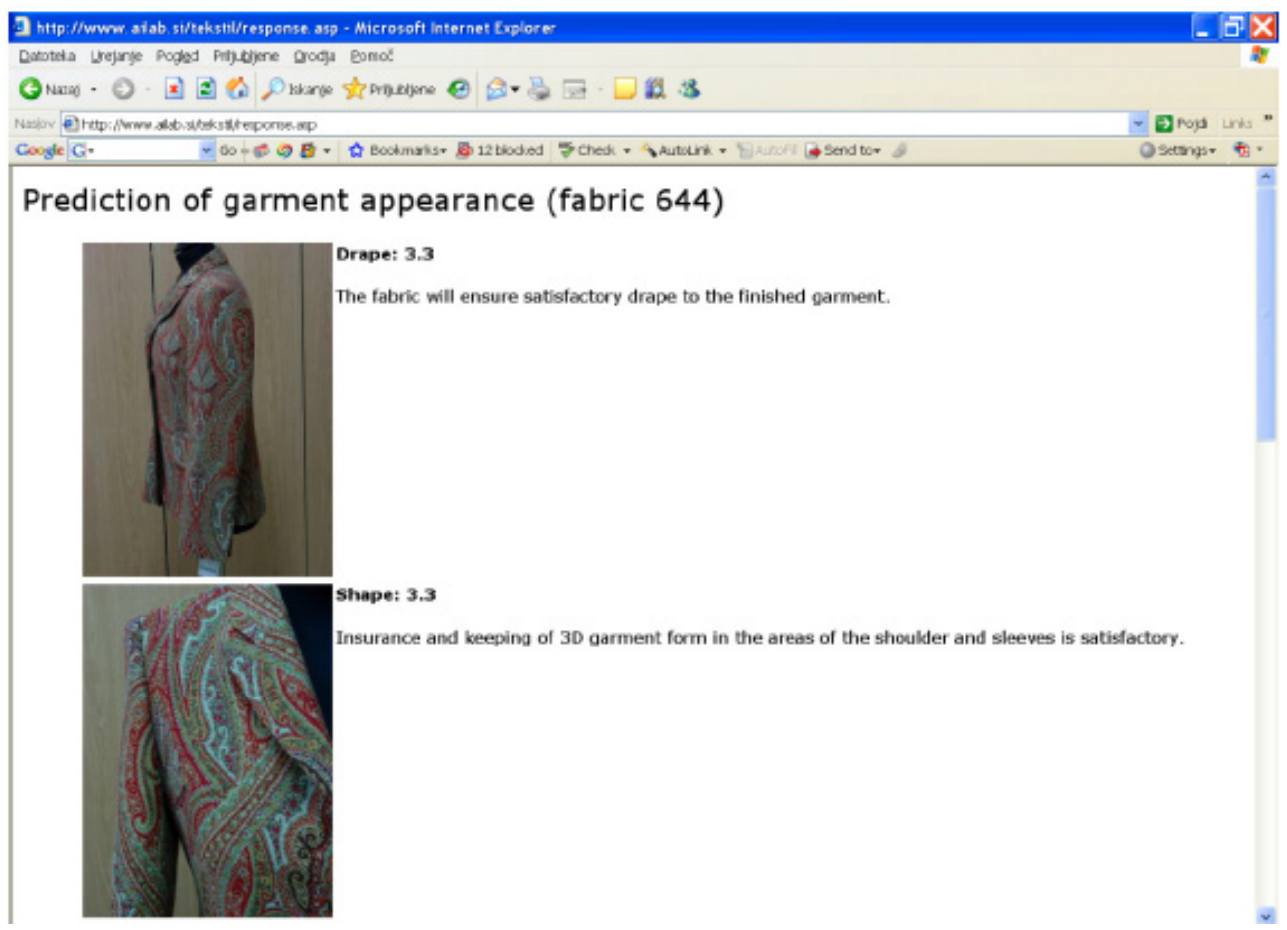


(Fig. 5) Contd......

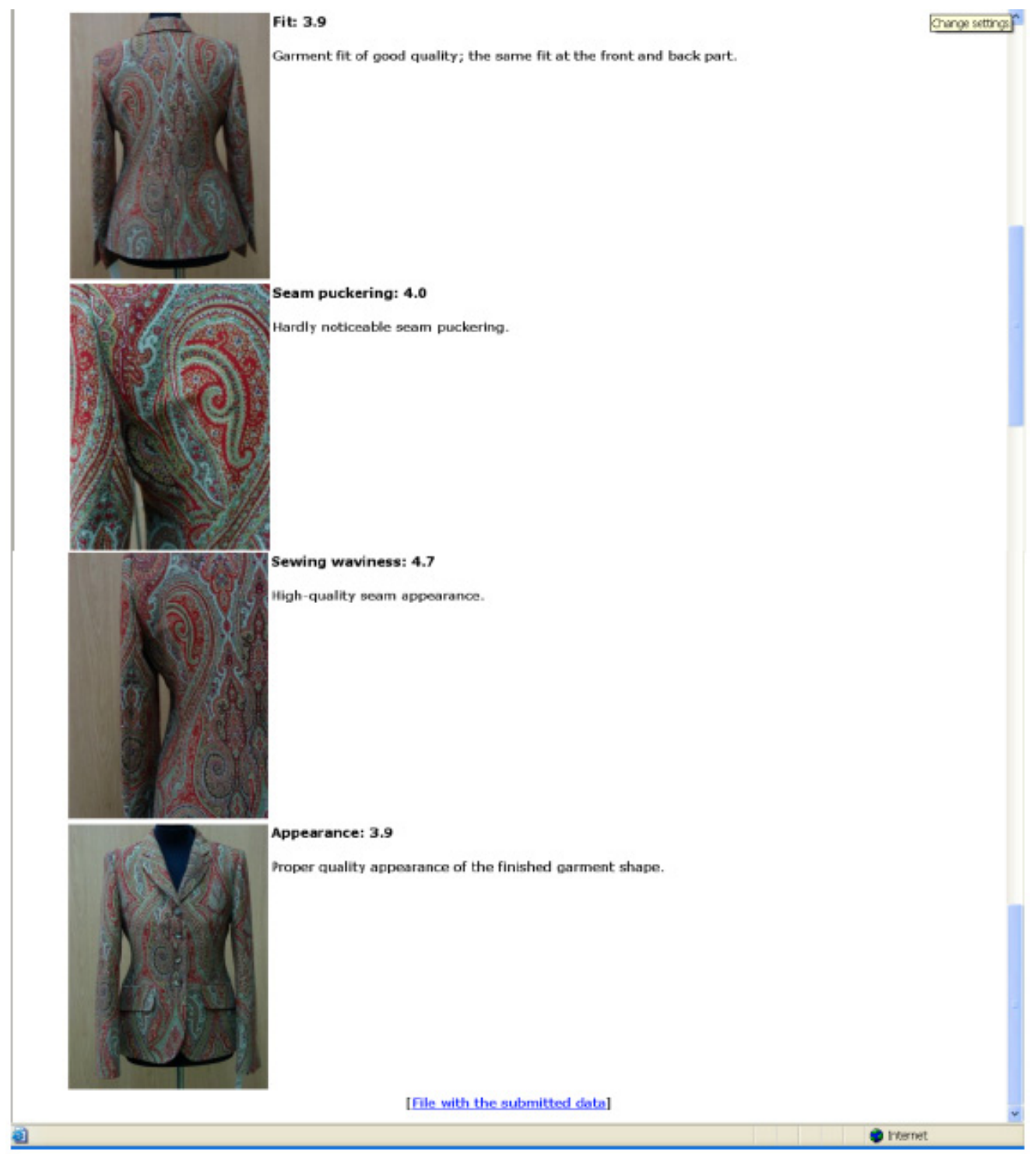

Fig. (5). An example of prediction.

(where the attributes are the parameters of mechanical and physical properties of the fabrics used in the manufacture of jackets, and the classes are the factors of the quality of the ladies' jackets in question), we have come to the conclusion that there is a direct correlation between the parameters of fabric mechanical and physical properties and the grade of garment appearance quality reached. A number of parameters of mechanical and physical properties impact each individual factor of garment appearance quality. The intelligent system for predicting garment appearance quality has been built on data basis containing the determined correlation of the parameters of fabric mechanical and physical properties and the grade of garment appearance quality.

The developed intelligent system for predicting garment appearance quality grade is of a particular applicative importance, as it can be used in engineering predictions and designing high-quality garments, while at the same time it offers important data on the quality requirements of particular parameters of fabric mechanical and physical properties, necessary to obtain the required garment appearance.
The system represents a necessary objective technology of measuring and evaluating garment appearance quality, since the existing conventional methods of subjectively evaluating garment appearance quality should be replaced by a new knowledge-based engineering method.

\section{REFERENCES}

[1] J. Geršak, "Investigation of influence of fabrics mechanical properties on clothing appearance / Istraživanje utjecaja mehaničkih svojstava tkanina na izgled odjeće", Tekstil, vol. 52, pp. 368-379, August 2003. (In Croatian).

[2] M. Žiberna-Šujica and A. Gačnik, Composition and uses offabrics / Kompozicija in uporabnost tkanin. Maribor: Visoka tehniška šola, 1979. (In Slovene).

[3] M. Žiberna-Šujica, and A. Pintarič, "Numerical evaluation of constructional parameters of fabrics / Numerično vrednotenje konstrukcijskih parametrov tkanin", in Proceeding book International conference of Innovation and modelling of clothing engineering processes, 1997, pp. 88-95.

[4] J. Geršak, Mechanical and Physical Properties of Textile Materials / Mehanske in fizikalne Lastnosti Tekstilnih Materialov. University 
of Maribor, Faculty of Mechanical Engineering, Department for textile material and design: Maribor, 2006. (In Slovene).

[5] K. Slater, Textile Mechanics. Manchester: The Textile Institute Manchester, 1977, Vol. 1.

[6] S. Kawabata, K. Ito, and N. Masako, "Tailoring process control", J. Textile Inst., vol. 83, pp. 361-373, March 1992.

[7] S. Kawabata, The Standardization and Analysis of Hand Evaluation, The Hand Evaluation and Standardization Committee, $2^{\text {nd }}$ ed. Osaka: The Textile Machinery Society of Japan, 1980.

[8] J. Geršak, "Pozna oblačilna industrija material?", in Book of Proceedings - Clothing Engineering '98, 1998, pp. 38-44. (In Slovene).

[9] D. Z. Pavlinić, and J. Geršak, "Evaluation of the appearance clothing quality / Vrednovanje kakvoće izgleda odjeće", Tekstil, vol. 53, pp. 497-542, October 2004. (In Croatian).

[10] J. Geršak, Development of the System for Qualitative Prediction of Garments Appearance, in Proceeding of the $30^{\text {th }}$ Textile Research Symposium at Mt.Fuji in the New Millennium, 2001, pp. 135-144.

[11] DIN 60001 - 4: Textile Faserstoffe; Kurzzeichen, August, 1991. (In German)

[12] DIN 53 853: Bestimmung der Fadendichte von Geweben, DIN Deutsches Institut für Normung, Taschenbuch 17, Berlin 1984. (In German).
[13] DIN 53 854: Gewichtsbestimmungen an textilen Flächengebilden mit Ausnahme von Gewirken und Gestricken, DIN - Deutsches Institut für Normung, Taschenbuch 17, Berlin 1984. (In German).

[14] DIN 61101-1, Ausgabe: 1979 - 01, Gewebebindungen; Allgemeine Begriffe, Grundbindungen, August, 1991. (In German).

[15] A. De Boss, The FAST System for Objective Measurement of Fabric Properties, Operation, Interpretation and Applications. Sydney: CSIRO Division of Wool Technology, 1991.

[16] D. Z. Pavlinić, "Predicting Clothing Appearance Quality / Napovedovanje Kakovosti Izgleda Oblačil", Ph.D. thesis, University of Maribor, Maribor, Slovenia, 2005. (In Slovene).

[17] D. Zavec Pavlinić, J. Geršak, J. Demšar, and I. Bratko, "Predicting seam appearance quality", Textile Res. J., vol. 76, pp. 235-242, March 2006.

[18] J. Demšar, and B. Zupan, Orange, 2004, Available from: http://magix.fri.uni-lj.si/orange/.

[19] J. H. Zar, Biostatistical Analysis, 4th ed. New Jersey: Prentice Hall, Englewood Clifs, 1998.

[20] M. Bona, Textile Quality, Physical Methods of Product and Process Control. Biella: Textilia, Istituto per la Tradizione e la Technologia Tessile, 1994.

(C) Pavlinic and Geršak; Licensee Bentham Open.

This is an open access article licensed under the terms of the Creative Commons Attribution Non-Commercial License (http://creativecommons.org/licenses/by$\mathrm{nc} / 3.0 /$ ), which permits unrestricted, non-commercial use, distribution and reproduction in any medium, provided the work is properly cited. 